\title{
La extradición y la cooperación internacional. Falta de justicia, legitimidad o incapacidad del Estado colombiano: su historia*
}

\author{
Rodrigo Orlando Osorio Montoya** \\ Recibido: 7 de julio de 2017 • Aprobado: 7 de julio de 2017
}

\section{Resumen}

La extradición es la figura jurídica judicial de mayor expresión en materia de cooperación internacional; siendo los casos más notorios los de terrorismo, narcotráfico, blanqueo de capitales, armas, trata de personas, organizaciones criminales y demás conductas punibles conexas a los anteriores, así como los delitos contenidos en el Estatuto de Roma.

Esta figura cooperativa en algunos estamentos ha superado una serie de barreras de conveniencia política, económicas, jurídicas y sociales, convirtiéndose en una institución más viable y de mayor validez, pues ha pasado de ser una política de gobierno a ser una política estatal, además de ampliar su espectro de aplicabilidad, pasándose de la simple remisión de criminales a la reciprocidad de información, investigación, asistencia judicial, entre otros.

Es así que los países se encuentran hoy con la obligación internacional de efectuar y ratificar tratados en donde se generen compromisos de asistencia mutua en materia de cooperación internacional, basados en el principio o denominada formula del

\footnotetext{
" Este artículo es producto de la investigación: "La extradición y la cooperación internacional: falta de justicia, legitimidad o incapacidad del Estado colombiano". Efectuada en la Universidad Católica Luis Amigó, 2017, Medellín, Colombia, con el grupo de investigaciones Jurídico-Sociales - Jurisol, Medellín, Colombia. DOI: https://doi.org/10.15332/s1900-0448.2018.0048.07

“" Abogado de la Universidad de Medellín, Colombia. Especialista en Cultura Política y DD. HH. de la Universidad Autónoma Latinoamericana de Medellín, Colombia. Magíster en Derecho de la Universidad de Medellín, Colombia. Docente universitario e instructor policial, coordinador del área penal de la Funlam, Medellín, Colombia. Litigante en asuntos penales. Correo electrónico: rodrigo. osoriomo@amigo.edu.co, abopol@hotmail.com
} 
latín: aut dedere aut judicare (extraditar o juzgar), emanado desde los convenios de Ginebra de 1949, con el propósito de que si el estamento está imposibilitado de juzgar al criminal o desea entregarlo a la nación requirente, este pueda ser procesado por el solicitante.

Es de aclarar que esta norma se hizo a un lado durante décadas, tiene su reaparición legal en los artículos 8 y 9 del proyecto de código de crímenes contra la paz y la seguridad de la humanidad de 1996, en donde se trataba tímidamente este principio y el de jurisdicción universal. Lo anterior se retoma en 1998 al adoptarse el Estatuto de Roma de la Corte Penal Internacional.

Palabras clave: extradición, soberanía, justicia, tratados internacionales, debilidad estatal, INTERPOL, cancillería, ministerios.

\title{
EXTRADITION AND INTERNATIONAL COOPERATION. LACK OF JUSTICE, LEGITIMACY OR INCAPACITY of the Colombian State: its history
}

\begin{abstract}
Extradition is the most important judicial figure in international cooperation; the most notable cases being terrorism, drug trafficking, money laundering, weapons, trafficking in persons, criminal organizations and other punishable conducts related to the above, as well as the crimes contained in the Rome Statute.

This cooperation figure in some estates has overcome a series of political, economic, legal and social barriers, becoming a more viable and more valid institution, since it has gone from being a government policy to being a state policy, in addition to extending its scope of applicability, going from the simple referral of criminals to reciprocity of information, investigation, judicial assistance, among others.

Thus, countries today have the international obligation to make and ratify treaties where mutual assistance commitments are generated in the field of international cooperation, based on the principle or Latin formula called: aut dedere aut judicare (extradite or judge), issued since the Geneva Conventions of 1949, so that if the state is unable to prosecute the offender or wishes to surrender it to the requesting nation, the offender may be prosecuted by the petitioner.

It is to be clarified that this regulation was set aside for decades and has its legal reappearance in articles 8 and 9 of the draft code of crimes against the peace and
\end{abstract}


security of mankind of 1996, where this principle and that of the universal jurisdiction were timidly addressed. This was taken up again in 1998 when the Rome Statute of the International Criminal Court was adopted.

Keywords: Extradition, sovereignty, justice, international treaties, state weakness, INTERPOL, ministry of foreign affairs, ministries.

\section{A extradição e a cooperação internacional. FALTA de JUSTiÇA, LEgitimidade OU inCAPACIDAde do EsTAdo COLOMBIANO: SUA HISTÓRIA}

\section{Resumo}

A extradição é a figura jurídica judicial de maior expressão em matéria de cooperação internacional; sendo os casos mais notórios os de terrorismo, narcotráfico, branqueamento de capitais, armas, tráfico de pessoas, organizações criminosas e demais condutas puníveis conexas às anteriores, assim como os delitos estabelecidos no Estatuto de Roma.

Esta figura cooperativa em alguns estamentos tem superado uma série de barreiras de conveniência política, econômicas, jurídicas e sociais, convertendo-se em uma instituição mais viável e de maior validez, ora tem passado de ser uma política de governo ao ser uma política estatal, além de ampliar seu espectro de aplicabilidade, passando da simples remissão de criminosos à reciprocidade de informação, investigação, assistência judicial, entre outros.

É assim que os países encontram-se hoje com a obrigação internacional de efetuar e ratificar os tratados nos quais se gerem compromissos de assistência mútua em matéria de cooperação internacional, baseados no princípio ou denominada formula do latim: aut dedere aut judicare (extraditar ou julgar) emanado nos convênios de Genebra de 1949, com o objetivo que se o estamento está impossibilitado para julgar ao criminoso ou deseja entregá-lo à nação requerente, o criminoso seja processado pelo solicitante.

Deve-se esclarecer que esta forma foi ignorada durante décadas, tem sua reaparição legal nos artigos 8 e 9 do projeto do código de crimes contra a paz e a segurança da humanidade de 1996, na qual se tratava timidamente este princípio e o do jurisdição 
universal. O anterior se retoma em 1998 ao se adotar o Estatuto de Roma da Corte Penal Internacional.

Palavras-chave: extradição, soberania, justiça, tratados internacionais, debilidade estatal, INTERPOL, chancelaria, ministérios.

\section{Introducción}

La extradición es una figura jurídica compleja y compuesta igual que la construcción de la palabra. Lo primero que debemos establecer es el significado del vocablo extradición, siendo esta, como indicamos, una palabra compuesta entre el griego "ex": fuera y el latín "traditio": entregar (Sánchez, 1993), la cual comporta en la mayoría de países un trámite mixto ante dos ramas del poder público institucional: la rama ejecutiva y la rama judicial. Sin embargo, algunas naciones optan por un trámite administrativo o de una sola vía. No obstante, para abordarla debemos tener claridad además sobre su concepto, historia nacional e internacional, clases de extradición y práctica o litigio de la misma.

La extradición se debe entender como la figura de cooperación internacional por excelencia, cuyo objetivo principal en primer término es la de combatir el delito, la impunidad de las conductas criminales, simplificar las formalidades y permitir la ayuda mutua en materia penal; iniciando con la solicitud de un Estado requirente o el ofrecimiento del estamento que sirve de albergue, para entregar a una persona o personas vinculadas formalmente a una investigación penal o condenadas mediante sentencia en firme.

En segundo lugar, la extradición busca principalmente estrechar los lazos de amistad, solidaridad y de cooperación existentes entre los países en contra de la escalada de los criminales y sus delitos a nivel internacional, para hacer imperar la justicia en el ámbito del área penal y dentro del marco de los derechos humanos.

En concordancia con lo dispuesto anteriormente, es importante anotar que, de conformidad con Sánchez y Calderón (2017):

Al ser concebidos como universales, los derechos humanos no deberían tener fron-
teras ni nacionalidad, puesto que están dirigidos a todos los seres humanos. Al ser
universales, trascienden las fronteras y al dirigirse hacia la protección de los indivi-
duos, se deben dejar a un lado las ciudadanías o nacionalidades. Por lo tanto, son 
los Estados los que tienen la obligación de garantizar a cualquier individuo su cum-

plimiento, sin importar si es o no nacional del Estado en que se encuentre. (p. 56)

Debemos decir que esta figura de cooperación internacional es un procedimiento que de ninguna manera se trata o se debe tomar como proceso penal, dado que no existe contradicción del acervo probatorio enviado por el estado requirente en el país donde se encuentra la persona solicitada, y mucho menos se efectúan raciocinios de responsabilidad penal, toda vez que se estaría colocando en tela de juicio la soberanía del estamento solicitante.

Sin embargo, el procedimiento actual desconoce los principios de la extradición, los cuales son sus normas rectoras que iluminan un tema de tanta trascendencia para la vida de una persona, su familia, sus víctimas y para el estamento mismo, aunado a la falta de claridad en el mismo por lo concreto que resulta su consagración en un puñado de artículos de la legislación penal interna, haciéndese necesario una regulación mediante tratado público, en donde intervengan y confluyan la normativa internacional, dado que con lo que se cuenta, se vive y representan los casos de cooperación internacional en la materia, es con la sistemática y constante vulneración a los derechos humanos y garantías de todos los intervinientes en este procedimiento.

\section{Metodología}

Esta investigación se realizó mediante la recopilación documental y lectura sistemática de fuentes documentales de carácter primario y secundario. Los primarios son los documentos oficiales que comprenden: informes de gestión gubernamental, leyes, decretos y resoluciones, crónicas noticiosas, comunicados de las organizaciones sociales y políticas, entre otros. Los secundarios se refieren a la lectura de revistas, análisis y columnas de opinión de medios.

Una segunda etapa consistirá en clasificar y sistematizar la información obtenida, a partir de las fichas de contenido textual y descriptivo. En una tercera esfera, ha de elaborarse la secuencia de redacción de la síntesis y procesos inferenciativos que dieron nacimiento al resultado final del texto.

\section{Reflexión inicial}


Los sistemas de cooperación internacional, tales como la extradición, la ayuda jurídica, los tribunales ad hoc y permanentes, entre otros, hoy representan un sistema de derecho penal internacional integral, que aún se encuentra en formación, el cual no reemplaza el sistema interno, por el contrario, lo nutre: "derecho internacional penal", y le es complementario (Corzo y Corzo, 2006).

De igual manera, con este régimen lo que se persigue es combatir la injusticia e impunidad de aquellas conductas punibles que afecten o lesionen los intereses de los Estados, o que por su crueldad y vulneración a los derechos humanos llamen la atención o afecten la comunidad internacional, haciendo de lado lo absoluto del derecho de soberanía y relativizándose en aras de no permitir que los criminales utilicen sus países como refugios, luego de lastimar los intereses a tutelar por otra nación o la colectividad mundial. Es en lo anterior, que la ayuda jurídica y la extradición se convierten en las herramientas por excelencia de la cooperación internacional para así localizar bienes y personas, además de investigar, capturar, procesar, condenar o solicitar a los responsables de las ofensas penales hacia un determinado país (Corzo y Corzo, 2006).

En consecuencia, es estar de cara a las extradiciones, tener un elemento de asistencia internacional, con el cual se entra a prestar amparo en contra de la impunidad y a favor de la justicia cuando se cometen conductas punibles en otros Estados, y el victimario pretenda evadir su responsabilidad penal escondiéndose en otro territorio o delinca en su propia región en disfavor de ciudadanos internacionalmente protegidos o en virtud del principio "protección a los suyos". Esto último, es la norma rectora que se predica de los países que salvaguardan los derechos de sus ciudadanos, se encuentre donde se encuentren (Hernández, 2014).

Al pensar en extradición, visualizamos esta figura jurídica regulada a través de un tratado público internacional, existente en aras de garantizar el debido proceso y la transparencia de sus procedimientos. Sin embargo, en algunos países como Colombia, la extradición es un acto complejo que requiere la intervención de dos ramas del poder público para su aprobación, pero se genera de forma extraordinaria a través de la ley como un procedimiento, teniéndose descartado que sea un proceso, vulnerándose los derechos humanos y fundamentales de las personas capturadas con dichos fines, de su familia y en algunos casos de las mismas víctimas, dado que no son pocos los procesos fallidos (Hernández, 2014). 


\section{De la historia de la extradición en materia internacional}

\subsection{Antigüedad}

Las solicitudes de cooperación entre los pueblos en materia de extradición, ha estado presente para exigir la entrega de las personas que de alguna manera han ofendido, trasgredido o violado la ley de un lugar. Partiendo de los textos sagrados, encontramos historias como la de Sansón, quien desde antes de nacer estaba predestinado a liberar a Israel de los Filisteos; según la madre del nasciturus, un ángel le predijo que su hijo liberaría al pueblo israelí, pero ella no debía tomar ni vino, ni sidra, ni comer nada impuro; además Sansón no debía cortarse nunca el cabello (La Biblia: Jueces, 1960).

Cuando Sansón crece, parte a conocer las diferentes ciudades filisteas en busca de suerte, conociendo y enamorándose de una joven filistea llamada Timnat. Desde la boda tiene problemas con los filisteos asistentes, a los que al final termina matándolos, por lo que su suegro entrega a Timnat como esposa a otro hombre. Sansón se enfurece y prende fuego a las cosechas para vengarse; los filisteos dan muerte a su mujer quemándola viva, a lo que Sansón responde acabando con los homicidas. Tras esto, Sansón se va de tierras filisteas y vuelve a Israel, pero los filisteos solicitan su entrega a los israelitas para que responda por sus cargos de homicidio (Levoratti y Trusso, 2016).

En realidad, la figura jurídica de solicitar por parte de un territorio a una persona por conductas criminales es el resultado del acuerdo histórico de las voluntades entre los Estados de cooperar entre ellos, es por esto que tiene una alta carga e influencia ideológica, económica y política. Por ejemplo, en el año1274 a. C. se enfrentaban en lo que se conocería como la batalla de Qadesh los ejércitos de Ramsés II y los del rey hitita Muwatalli, en tierras de lo que hoy es Siria. La guerra se generó porque los hititas se apoderaron de Siria, territorio perteneciente en ese momento a Egipto, asentándose por siglos y volviendo la tierra muy productiva a través de la cosecha. El faraón se propuso acabar con el poder de los hititas y atacó la ciudad de Qadesh, localidad fronteriza y clave comercial.

De nuevo, los egipcios llenos de confianza por su superioridad numérica y entrenamiento militar dividieron sus escuadras y acamparon; pero Muwatalli decidió 
atacar en emboscada nocturna, matando y tomando rehenes, Sin embargo, Ramsés al día siguiente contraatacó e hizo valer sus armas y el rey se entregó y depuso. A partir de lo anterior, Ramsés II aceptaría siempre y cuando se acordara entre las partes a extraditar a los criminales y refugiados políticos, generándose así el primer tratado de extradición conocido y documentado en la historia del ser humano (Revista de Historia, 2016).

\subsection{Edad media}

A reglón seguido, el segundo acuerdo en materia de extradición de relevancia histórica fue el generado en la época del feudalismo. La extradición se tenía como una forma de protección patrimonial, debido al acuerdo entre la nobleza y los señores feudales de preservar sus bienes, de esta manera quien atentara en disfavor de la propiedad de uno de los del pacto y se refugiara en otro territorio, debía ser devuelto para que respondiera por su ofensa (Sánchez, 1993).

De igual manera, en el calendario de 1376, entre Francia y la región del sacro imperio romano (Italia), se genera otro episodio histórico importante en la materia. En estos años la única solicitud de extradición era por delitos políticos, pero en 1765 la lista se amplía a los delitos comunes más graves. Con la llegada de las ideas liberales, el constitucionalismo moderno y la concepción de un nuevo modelo de Estado bajo las banderas de la revolución francesa, se determinó el fin de la utilidad de la figura de la extradición para solicitar personas solo por delitos políticos limitada a los crímenes de naturaleza común, apartándose de la idea de usarla como un arma política para convertirse en un arma jurídica que garantizaría la esencia inmutable de los valores del hombre (Sánchez, 1993).

\subsection{Modernidad}

Luego, hacia el año 1794, entre los Estados Unidos de América e Inglaterra cuando todavía existían problemas entre los Estados y luego de la guerra de independencia sin resolver, se generó un acuerdo que tenía como óbice los delitos de homicidio y falsedad. Este acuerdo fue muy particular, dado que los tratados antiguos en la materia versaban sobre multiplicidad de delitos tales como el homicidio, amotinamiento, piratería, rebelión, bigamia, entre otros, los cuales no guardaban relación entre sí y que son los convenios actuales que se especifican en un delito 
en particular o en una lista corta de ellos, teniendo claro la conexidad entre una conducta punible y otra (McNabb, 2013).

Se comienza entonces a gestar una corriente de ideas, representadas en tratados internacionales, sobresaliendo el firmado en el 27 de marzo del año 1802 en Amiens, Francia. El acuerdo dio fin a la guerra iniciada en 1972 de Francia contra los países europeos con monarquía. Napoleón Bonaparte generó la iniciativa de paz, la cual no fue fácil, dado que un punto pétreo era la propuesta británica de conservar todas sus colonias y Napoleón exigía libertad e igualdad para todos los pueblos. La consigna del líder ítalo francés era que, si no se llegaba a un acuerdo, atacaría Inglaterra que estaba en crisis económica y financiera; además, el zar Pablo I, se unió con Dinamarca, Suecia y Prusia, para frenar el expansionismo británico en el mar Báltico, unidad que se denominaría la liga de los neutrales y que desaparecería a un año de firmarse el tratado tras el homicidio del zar. El acuerdo no sentó las bases para una paz estable, por no generarse la libertad e igualdad solicitada por Napoleón para la mayoría de las colonias inglesas. Sin embargo, se logró el intercambio de todos los prisioneros de guerra, asegurándose la entrega de la delincuencia común con la excepción que no existiría pronunciamiento sobre los delitos políticos (Godechot, 1969).

Es el turno en este recorrido para la legislación belga. Era el año de 1833, en donde se introducen los supuestos de que la conducta debía ser un crimen tanto en el país requirente como en el requerido, además debía ostentarse el carácter de delito común. Los anteriores lineamientos están presentes en cada una de las legislaciones que contemplan la extradición como figura cooperativa entre los pueblos, siendo América y Colombia unos adoptivos del sistema belga (Nicholls, Montgomery, Knowles, Doobay y Summers, 2013).

Bajo la expedición de la Ley de 1870 en Gran Bretaña, se comienzan a generar las limitaciones al poder de los estamentos a extraditar, contenía esta normativa la negativa de entrega al país solicitante por delitos de naturaleza política, además de no poder extraditar por conductas establecidas como criminales por el derecho penal interno (McNabb, 2013).

\subsection{Posmodernidad}

Hacia la mitad del siglo XX, entre España y Reino Unido se presenta una discusión jurídica de cara a la extradición, dado que la primera tenía como piedra 
fundacional de su derecho al área civil, mientras que la segunda al common law y la exigencia prima facie evidencia de la responsabilidad penal. Esto causó que el país español perdiera el interés en un tratado internacional con el Reino Unido, convirtiéndose en el escondite de los delincuentes. La presión del estamento inglés y de la percepción de criminalidad de los españoles obligó a un nuevo acuerdo bilateral hacia mitad de la década de los ochenta, dándose un procedimiento general sin importar el derecho imperante en el país (Nicholls, Montgomery, Knowles, Doobay y Summers, 2013).

\section{De la historia de la extradición en Colombia}

\subsection{De los sistemas legales y sus reformas para extraditar}

En primera instancia se hará referencia a los tres sistemas en materia de extradición y los que Colombia ha ostentado legalmente:

El primero de ellos por vía administrativa o gubernativa. En este sistema administrativo o gubernativo, la cabeza de la rama ejecutiva en el poder público de manera exclusiva detenta la potestad para conocer y resolver sobre la solicitud de extradición, haciendo desaparecer la teoría del acto complejo o compuesto, evaporando el control judicial de una actuación que es limitante y en algunos casos vulnerante de los derechos humanos y fundamentales (Huertas, Trujillo, Gonzalo y Sanabria 2007; Huertas, Baracaldo, Eliseo, Pinzón y Peña, 2008); el cual el país utilizó para introducir por primera vez a la extradición en su ordenamiento jurídico en 1936 (Corte Constitucional, 2000).

El segundo sistema es el judicial, donde conocen únicamente los jueces, los tribunales y las autoridades jurisdiccionales, siendo un sistema simple, pudiendo también como el primero en convertirse en una dictadura de línea judicial. Colombia nunca en su historia a obstinado por tener este sistema como reglamentario en materia de cooperación jurídica penal internacional (Huertas, 2011; Huertas y Amaya, 2016).

Por último, se encuentra el sistema mixto, en donde su trámite combina los dos sistemas anteriores, estando la oferta o concesión de la extradición en el ejecutivo, pero requiriendo del aval jurisdiccional la potestad facultativa del gobierno (Corte Constitucional, 2009). 
Especialmente, en el año de 1986 el presidente de la República para ese entonces, tiene la iniciativa de que el país acoja este sistema, sobre la base de poder brindar más garantías legales a las personas que se enfrenten a la extradición (Huertas y Amaya, 2016).

\subsection{De la génesis y las reformas legales colombianas en materia de extradición}

Colombia ha sido de los primeros Estados en suscribir convenios de cooperación internacional, unos bien pensados y otros se han ido analizando y corrigiendo sobre su ejecución. En el año de 1888, se adhiere a participar en la lucha contra el crimen, teniendo como motivación para ello: que el delito tenía que ser atacado más allá de las fronteras nacionales y evitar que el país se convirtiera en refugio para los delincuentes propios e internacionales. Además, inserta dentro de su legislación sustancial penal, el tráfico de sustancias controladas como causal de extradición y en el estatuto procedimental se establece el procedimiento de extradición por vía administrativa mediante el Decreto 2300 de 1936 (Huertas y Amaya, 2016).

En el año de 1936 y mediante la Ley 95 se expide el Estatuto Sustancial Penal; el cual, consagró el concepto sobre la extradición:

La extradición se concederá u ofrecerá de acuerdo con los tratados públicos. A falta de tratados públicos, el Gobierno ofrecerá o concederá la extradición conforme a los trámites establecidos en el Código de Procedimiento Penal. No se concederá la extradición de colombianos ni la de delincuentes político-sociales. (Ley 95, artículo 9)

Dos años más tarde, se establece en el estatuto de procedimiento penal el trámite para materializarla, y en 1941 se presenta modestamente una reforma que introduce el tema de los estupefacientes a la temática de la extradición (Archila, 1938).

En realidad, Colombia consagró vía legal y conceptualmente lo atinente a la extradición como forma de cooperación con otros países, pero no sería hasta el año de 1979, que el entonces embajador de Colombia ante los Estados Unidos de América, el ingeniero civil y liberal Virgilio Barco Vargas, quien en 1986 sería presidente de la República de Colombia (E1 Tiempo, 1997), tiene la iniciativa de brindar más garantías legales a la extradición, solicitando la reforma a los códigos penales, eliminándose el tratamiento administrativo y pasando a un sistema mixto. 
De esta manera, al artículo 9 se le añade un segundo inciso: “(...) y previo dictamen favorable de la Corte Suprema de Justicia (...)”; ratificándose con esto la figura de la extradición mediante la Ley 27 de 1980 y dándole mayor legitimidad y validez a la misma, concretándose lo anterior en el tratado de extradición del año de 1888 entre Colombia y EE. UU. (Melo, 1994).

De hecho, bajo la batuta presidencial de Belisario Betancur Cuartas, durante el periodo constitucional comprendido entre los años de 1982-1986, iniciando el mandato este militante del partido conservador, entró en vigor el 4 de marzo el tratado de extradición entre Colombia y los Estados Unidos. Inmediatamente el Estado del norte radicó varias solicitudes de extradición, pero la cabeza del ejecutivo no accedió a estas por ideologías políticas, consideraciones nacionalistas y fundadas en la creencia de que el pueblo la rechazaría porque el dinero del narcotráfico hacía tránsito a una economía paralela que generaba empleo legal de manera indirecta (Melo, 1994).

Pero, a finales del año de 1983, el abogado Rodrigo Lara Bonilla asume como ministro de Justicia e inicia una guerra frontal contra las drogas, implementando en los procesos penales, pérdida del poder dispositivo, embargos y extinción de dominio de los bienes de los carteles, así mismo, se inicia un respaldo a las capturas con fines de extradición. Como respuesta a lo anterior, los narcotraficantes ordenaron la muerte del ministro Lara el 30 de abril de 1984, lo que obligó al presidente Belisario a declarar el estado de sitio y comenzar a cambiar su postura sobre esta figura de cooperación internacional (Donadio, 2016).

Finalmente, el 6 de noviembre de 1985 el grupo guerrillero M-19 se tomó el Palacio de Justicia, operación subversiva efectuada con el financiamiento de dineros del narcotráfico y que hizo cambiar totalmente la visión del mandatario, pues para esos días el problema de la droga no era una prioridad, la prelación se centraba en atender a los grupos insurgentes, quienes generaban mayor violencia del país. Sin embargo, el narcotráfico financiaba acciones de rebelión, pues una cárcel en EE. UU. era el mayor temor de los carteles y por ello se convierte la extradición en una herramienta eficaz y expedita contra estos (Melo, 1994).

El fin de la era Belisario y el comienzo de la era Barco, deja un panorama de violencia extrema en contra de los defensores de derechos humanos, periodistas, miembros de la rama judicial y fuerzas armadas, así como contra todo político que se atreviera a tocar el tema de la extradición. En la era del presidente Virgilio Barco Vargas, entre los años de 1986 a 1990, se enfrentó a pocos meses del inicio de su mandato a la modificación de la postura de la Corte Suprema de Justicia con la 
declaratoria de la inexequibilidad de la Ley 27 de 1980, que incorporaba al derecho interno el tratado de 1979. El fallo se basó en que el presidente para la época no fue quien sancionó la ley, la firma que aparecía era la del ministro Zea Hernández, el cual actuaba como delegado presidencial. Esta declaratoria de la inexequibilidad quitaba un arma de temor entre los criminales, por ello el 14 de diciembre de 1986 a solo dos días del fallo de la alta corporación, el gobernante Barco sancionó la Ley 68 de 1986 reviviendo el tratado internacional de extradición con los Estados Unidos de América.

De igual manera, la retaliación no se hizo esperar por parte de los carteles de la droga en cabeza de Pablo Emilio Escobar Gaviria, dado que a los dos días de la sanción presidencial se genera el homicidio del periodista y director del diario El Espectador: Guillermo Cano, fuerte detractor de narcotráfico y sus líderes criminales; ese mismo año se presenta el violento deceso de Jaime Pardo Leal, abogado de la Facultad de Derecho y Ciencias Políticas de la Universidad Nacional de Colombia, juez, magistrado del Tribunal Superior de Cundinamarca y candidato a la Corte Suprema de Justicia, fundador de la Asociación Nacional de Empleados de la Rama Judicial - ASONAL (Donadio, 2013).

Un año más tarde el ejecutivo en medio del desespero por la pérdida del poder y del control estatal insiste en la extradición, generando el 5 de enero de 1988 las órdenes de captura contra la cabeza del cartel de la ciudad de Medellín, pero esta iniciativa fue frenada por el Consejo de Estado y sumado a esto los narcotraficantes reaccionan con el atentado a la sede principal en Bogotá del departamento, seguido en agosto 18 de 1989 por la muerte del caudillo liberal Luis Carlos Galán, haciendo que el gobierno decretara el estado de sitio reviviendo la extradición administrativa sin ningún éxito, pues los magistrados y jueces seguían amenazados, los candidatos presidenciales y miembros de la fuerza pública seguían muriendo y convivía con esto el miedo a tomar decisiones políticas y judiciales (Salazar, 2003).

En los años de 1990 a 1994 llegó a la silla presidencial quien fuera allegado y jefe de debate del asesinado precandidato liberal Luis Carlos Galán, el señor César Gaviria Trujillo. Desde el inicio de su mandato, propuso continuar con una extradición tipo administrativa y una política de sometimiento a la justicia por parte de los narcotraficantes mediante el Decreto 2047 de 1990. Aunando esta legislación a otra normativa similar, llega la constituyente de ese mismo calendario que dio surgimiento a la Constitución de 1991, la cual en su artículo 35 prohibía la extradición de colombianos; lo cual dejaba ver la impotencia, fragilidad, 
ingobernabilidad en inferioridad del estamento colombiano de cara a las fuerzas ilegales del narcotráfico (Gaviria, 2016).

En los años de 1994 a 1998 llega a la presidencia Ernesto Samper Pizano, quien instala una comisión de verificación de la política de sometimiento de su antecesor, llegando a la conclusión de que debía mantenerse a Colombia sin extradición, pues el presidente con esta figura vapuleaba la soberanía del país al permitir que jueces foráneos con sus leyes procesaran a los colombianos; además agregaba que la extradición no era la única herramienta para luchar contra el narcotráfico y lo que debía generarse era una justicia que funcionara rápida y cumplidamente, para esto debía reformarse en aras de robustecer la administración de justicia. Con los anteriores argumentos, el ejecutivo desechó la solicitud norteamericana de envío de los cabecillas del cartel de Cali, los hermanos Rodríguez Orejuela, quienes estaban siendo solicitados por la Corte Distrital del distrito sur de Florida y la Corte de Nueva York por los delitos de narcotráfico, blanqueo de capitales y conspiración (Montes y Perea, 2005).

De igual manera, para este mandatario la extradición no era ni sería un tema de agenda como instrumento contra el narcotráfico, mientras los estamentos solicitantes no hablaran de corresponsabilidad, dado que sin demanda no existiría producción de drogas ilícitas y la guerra contra las drogas sería de todos. Esta propuesta al lado de la creación de una central mundial de inteligencia, era una estrategia en donde parte de sus armas de lucha contra el narcotráfico era la extradición regulada por tratados internacionales, con vigencia y jurisdicción para todos los Estados miembros de la ONU, dadas en el seno de la Asamblea General de las Naciones Unidas. Sin embargo, al interior de Colombia como en las ONU no fueron recibidas positivamente (Montes y Perea, 2005).

Al mismo tiempo que el mandatario de turno se oponía a la extradición y buscaba reparos a la aplicabilidad de la figura en el país, mientras no existiera consenso internacional y nacional en esta, el Senado adelantaba un proyecto de reforma constitucional al artículo 35. Sin embargo, el debate de la extradición finalizó porque no se dieron los términos de los debates.

El presidente Samper cambia de parecer y afirma al respecto que si lo que se buscaba era revivir la extradición a toda costa, la normativa de esta figura debía hacerse por ley y no ser materia constitucional, subrayando que era un arma poderosa para sacar de sus escondites a los criminales (Gaviria, 2016). 
La conclusión de la polarización del país, entre las ramas del poder público y entre la misma sociedad colombiana, se genera con el acto legislativo 01 del 16 de diciembre de 1997, en donde se devuelve la vida jurídica a la extradición en el artículo 35 de la carta magna colombiana sin retroactividad, sin la posibilidad de generarse por delitos políticos y pudiéndose regular por tratado internacional o por vía de ley. Es así como la extradición nacería y continuaría sin un tratamiento mediante tratado internacional y, por el contrario, tomaría fuerza su aplicación vía ley, siendo consagrada en los códigos penales y de procedimiento penal del año 2000 y en el 2004 por la Ley 600 y 906 seguidamente.

El 11 de septiembre del 2001, el mundo se estremecería con el ataque terrorista a la primera potencia del planeta, haciendo cambiar las prioridades en materia de seguridad y de derecho penal internacional, pasando a un segundo plano el delito de drogas ilícitas o estupefacientes y quedando en primer lugar el terrorismo (Osorio, 2015). Mientras tanto en Colombia y finalizando el mandato de Andrés Pastrana cobraría relevancia la extradición como principal herramienta de la lucha contra el narcotráfico, política de gobierno con continuidad bajo los años 2002 a 2010 con el presidente Álvaro Uribe Vélez, bajo la bandera de su programa de gobierno "la seguridad democrática", en donde se dan 1.149 extradiciones firmadas y ejecutadas; teniendo en cuenta que desde el año de 1984 cuando se reactivó la extradición hasta el año 2002 se han realizado unas 1.482, teniendo en cuenta las extradiciones de los jefes paramilitares luego del proceso de paz con las Autodefensas en el año 2005 (El Tiempo, 2010).

En el gobierno del presidente Juan Manuel Santos Calderón, la extradición pasó a un segundo plano, dado que ha centrado sus esfuerzos en el proceso de paz con la guerrilla de las Farc-EP; en este espacio se han generado polémicas decisiones como el tratamiento del narcotráfico y las conductas ligadas a este como conexos a los delitos de los integrantes de grupos paramilitares y guerrilleros. La Corte Suprema de Justicia en su Sala Penal, en auto 42.686 de febrero 12 del 2014, con ponencia del magistrado Gustavo Enrique Melo, precisó que el integrante del grupo armado ilegal en situación de conflicto puede postularse y ser inscrito en la justicia especial o transicional, siempre que la actividad del narcotráfico no resultare como la intención o pretensión principal en razón a su vinculación, pertenencia o militancia a la organización criminal. En similar sentido, se tiene en Colombia la sentencia C-577 del 2014 por parte de la Corte Constitucional. 
Es entonces procedente afirmar que las extradiciones en este periodo presidencial, se han centrado en la lucha contra las bandas y organizaciones criminales reductos de las autodefensas y guerrilleros no alineados al proceso de paz (Semana, 2016); y que de conformidad con Niño (2016), "Colombia ha estado alejada de las preocupaciones mundiales por dinámicas concernientes a su conflicto interno y demás variables" (p. 101).

Atendiendo lo dispuesto en líneas anteriores, es importante anotar en el marco de la temática propia de la extradición, la necesidad de analizar la posibilidad de contemplar:

La amnistía desde el punto de vista del Estatuto de Roma de la Corte Penal Internacional en el marco jurídico para la paz en Colombia, teniendo en cuenta que Colombia hizo la adhesión a las premisas jurídicas planteadas por la Corte Penal Internacional (CPI), enfocándose en tener en cuenta la gran cantidad de conductas vulneradoras de los derechos humanos que se han dado en el contexto de violencia que ha atravesado Colombia por años y que aún sigue afrontando. (Yañi, 2017, p. 40)

\section{Conclusiones}

La extradición es un tema con antecedentes históricos y ancestrales a nivel mundial, esencial en aras de contrarrestar el delito y aplicar justicia. Pero es un tema muy sensible y polémico, ya que se genera y debate entre unas complejas y enmarañadas políticas gubernamentales, pues es permeada por los factores políticos, económicos, sociales, de seguridad y del estado de las relaciones con determinado país. Lo anterior la hace confusa, irregular, subjetiva e injusta.

Al estudiar la Constitución Política de 1886, no se encuentra mención de esta figura jurídica. Al desaparecer la anterior carta magna y el nacimiento de la norma principal de 1991, nos encontramos que de igual manera no se hace ninguna referencia. Sin embargo, la impotencia y debilidad del Estado de cara a los fenómenos criminales que antecedieron y precedieron la Constitución del 91, obligó junto con la presión internacional a consagrarla en 1997.

La extradición es entonces un mecanismo jurídico de cooperación entre Estados, en donde se solicita a una persona por parte de un país, dado que violó su régimen penal y se encuentra en otro estamento. Esta herramienta de cooperación 
internacional puede ser de un sistema administrativo, jurisdiccional o mixto, dependiendo de su concepción política.

El tema de la extradición se ha planteado desde un lenguaje y mediante algunos términos que persuaden y conmueven, dando a entender que la figura está reglamentada en Colombia de manera garante y que cumple con los preceptos internacionales. Sin embargo, su concepción es eminentemente formal-normativa. En lo fáctico, en lo jurídico, por desgano ejecutivo y debilidad diplomática, han convertido el tratamiento de este tema en algo que atiende a imposiciones extranjeras y políticas, alejándose de tener un tratamiento bajo la observación de los derechos humanos y fundamentales.

Esta figura de cooperación internacional ha sido tratada a conveniencia por la presidencia en turno; sendos errores acompañan la extradición, pero más importante es la vulneración de los derechos humanos en estos. Sin embargo, el único cambio significativo fue la visibilización de una política antidrogas bilateral, con corresponsabilidades y un procedimiento mixto, aun con la carencia de un tratado internacional con todos los países que abogan por esta, convierte a la institución en una herramienta subjetiva y de aplicabilidad ambigua en unos y otros casos.

Lo anterior pone en riesgo el debido proceso como derecho fundamental, pues la dignidad, legalidad, respeto por las garantías mínimas como la no pena de muerte o cadena perpetua y presunción de inocencia, quedan vulnerables al cumplimiento de las palabras políticas y notas de cancillería al no existir una regulación propia para este tema.

Las obligaciones de los criminales y la declaratoria de responsabilidad por sus conductas ilícitas no son con el gobierno, lo son para con toda la sociedad, inclusive la internacional cuando sus acciones punibles rebasaron las fronteras, sin olvidar que estamos procesando un ser humano con derechos y permeado de garantías fundamentales. 


\section{Referencias}

Archila, J. (1938). Código Penal del 36. Bogotá: Editorial Cromos.

Corte Constitucional de Colombia. (24 de agosto del 2000). Sentencia C-1106. Extradición: naturaleza y cooperación internacional. M.P. Alfredo Beltrán Sierra.

Corte Constitucional de Colombia. (1 de abril del 2009). Sentencia C-243. Naturaleza jurídica de la extradición. M.P. Jorge Iván Palacio Palacio.

Corte Constitucional de Colombia. (14 de mayo del 2008). Sentencia C-460. Extradición: soberanía de Estado requirente y acto no es de juzgamiento. M.P. Nilson Pinilla Pinilla.

Corte Constitucional de Colombia. (6 de agosto del 2014). Sentencia C-577. Marco jurídico para la paz, justicia transicional. M.P. Martha Victoria Sáchica Méndez.

Corzo, V., y Corzo, E. (2006). El sistema penal internacional. Los nuevos desafíos de la Procuraduría General de la República, sexta época. Revista Mexicana de Justicia, (13), 15-35. México.

Donadío, A. (2013). Guillermo Cano, el periodista y su libreta. Bogotá: Edición Kindle.

Donadío, A. (2016). El asesinato de Rodrigo Lara Bonilla. Bogotá: Silaba. .

El Tiempo. (1997). El legado de Virgilio Barco. Recuperado de http://www.eltiempo.com/ archivo/documento/MAM-574266

El Tiempo. (2010). La política de seguridad democrática fue el más acertado logro del gobierno de Uribe en Boyacá. Recuperado de http:/www.eltiempo.com/archivo/documento/ CMS-7845437

Gaviria, A. (2016). Alguien tiene que llevar la contraria. Bogotá: Editorial Ariel.

Godechot, J. (1969). Europa y América en la época napoleónica. Barcelona.

Hernández, M. (2012). Extradición: del legado de la antigüedad a los principios normativo. Revista Principia Iuris, (18). Tunja.

Hernández, M. (2014). Cumplimiento de la garantía de la dignidad humana en el trámite de extradición. Bogotá: Editorial Ibáñez.

Huertas, O. (2011). Jurisprudencia penal internacional aplicable en Colombia. Revista Logos, Ciencia y Tecnología, 3(1), 240-242.

Huertas, O., y Amaya, C. (2016). Triada del derecho penal internacional. Colección de legislación internacional. Bogotá: Editorial Ibáñez.

Huertas, O., Trujillo, F., Gonzalo, 1., y Sanabria, J. (2007). El derecho al debido proceso y a las garantias judiciales en la dimensión internacional de los derechos humanos. Bogotá: Editorial Ibáñez. 
Huertas, O., Baracaldo, D., Eliseo, C., Pinzón, S., y Peña, J. (2008). El principio de igualdad y no discriminación a la luz del derecho internacional de los derechos humanos. Bogotá: Editorial Ibáñez.

Huertas, O., Jiménez, N., y Perdomo, M. (2015). La responsabilidad internacional del Estado colombiano en el sistema interamericano de derechos humanos (2006-2013). Revista Jurídica Piélagus, 14, 217-224.

La Biblia. (1960). Libro de los Jueces, 13-16. Bogotá: Reina Valera. Sociedades Bíblicas en América Latina.

Ley 27. (1980). Por medio de la cual se aprueba el tratado de extradición entre la República de Colombia y los Estados Unidos de América, frmado en Washington el 14 de septiembre de 1979. Diario Oficial n. 35.643. Bogotá: Congreso de la República. Recuperado de http://www.suin-juriscol.gov.co/viewDocument.asp?id=1698775

Ley 68. (1986). Por medio de la cual se aprueba el "Tratado de Extradición entre la República de Colombia y los Estados Unidos de América. Diario Oficial n. ${ }^{\circ}$ 37.733. Bogotá: Congreso de la República. Recuperado de http://www.suin-juriscol.gov.co/viewDocument. asp?id=1698781

Ley 600. (2000). Por la cual se expide el Código de Procedimiento Penal. Diario Oficial n. 44.097. Bogotá: Congreso de la República. Recuperado de http://www.alcaldiabogota. gov.co/sisjur/normas/Norma1.jsp?i=6389

Ley 906. (2004). Por la cual se expide el Código de Procedimiento Penal (corregida de conformidad con el Decreto 2770 del 2004). Diario Oficial: 45.658. Bogotá: Congreso de la República. Recuperado de http://www.alcaldiabogota.gov.co/sisjur/normas/Norma1. jsp? $\mathrm{i}=14787$

Levoratti, A., y Trusso, A. (2016). Libro del pueblo de Dios. Libro Los Jueces, capitulos 13-16. Primera edición. Navarra: Editorial Verbo Divino.

McNabb, D. (2013). Lawyer criminal. Recuperado de https://www.youtube.com/watch?v=vvqK8K1LtbE\&feature=youtu.be

Melo, J. O. (1994). Colombia es un tema: la lucha contra el narcotráfico: éxitos y limitaciones. Recuperado de http://www.jorgeorlandomelo.com/luchnarco.htm

Montes, M., y Perea, A. (2005). ¿Cómo el narcotráfico ha influido en la política criminal colombiana? 1978-1997. Bogotá: Pontificia Universidad Javeriana, Facultad de Ciencias Jurídicas.

Nicholls, C., Montgomery, C., Knowles, J., \& Doobay, S. (2013). M. the law of extradition and mutual assistance. 3. ${ }^{\mathrm{a}}$ edition. Oxford: Oxford University.

Niño, C. (2016, julio-diciembre). Exportación de conocimiento: Colombia como proveedor de seguridad para la lucha contra el terrorismo y el crimen internacional. Revista Via 
Inveniendi et Iudicandi, 11(2), 87-104. Recuperado de http://revistas.usantotomas.edu. co/index.php/viei/article/view/3277/3089

Osorio, R. (2015). Derecho Penal Internacional. Bogotá: Editorial Leyer.

Revista de Historia. (2016). La batalla de Qadesh, egipcios contra hititas. Recuperado de http:// revistadehistoria.es/la-batalla-de-qadesh-egipcios-contra-hititas/

Salazar, A. (2003). El profeta en el desierto: vida y muerte de Luis Carlos Galán. Bogotá.

Sánchez, C. (1993). Procedimiento para la extradición. México: Editorial Porrúa.

Sánchez, C., y Calderón, D. (2017, julio-diciembre). Geopolítica de los derechos humanos en las fronteras terrestres de Colombia en el primer periodo presidencial de Juan Manuel Santos. Revista Via Inveniendi et Iudicandi, 12. DOI: http://dx.doi.org/10.15332/ s1909-0528.2017.0002.02. Recuperado de http://revistas.usantotomas.edu.co/index. $\mathrm{php} / \mathrm{viei} /$ article/view/3752/3714

Yañi, J. (2017, julio-diciembre). Amnistía y proporcionalidad desde el punto de vista del Estatuto de Roma en el marco jurídico para la paz en Colombia. Revista IUSTA, 2(47), 35-57. DOI: http://dx.doi.org/10.15332/s1900-0448.2017.0047.02. Recuperado de http://revistas.usta.edu.co/index.php/iusta/article/view/3808 